\title{
Factors influencing thrombin generation measured as thrombin-antithrombin complex and calibrated automated thrombogram method in patients with advanced coronary artery disease
}

\author{
Ewa Stępień1, Dariusz Plicner', Agnieszka Branicka', Elżbieta Stankiewicz' , Agnieszka Pazdan', \\ Maria Śnieżek-Maciejewska², Izabela Górkiewicz', Bogusław Kapelak², Jerzy Sadowski² \\ 1 The John Paul II Hospital, Kraków, Poland \\ ${ }^{2}$ Department of Cardiovascular Surgery and Transplantation, Institute of Cardiology, Jagiellonian University School of Medicine, Kraków, Poland
}

\begin{abstract}
Introduction. Haemostatic factors play an important role in atherothrombosis. Thrombin generation is a crucial stage of blood coagulation. Objectives. Comparison of different thrombin generation markers: thrombin-antithrombin complex (TAT) generation and calibrated automated thrombogram method (CAT). Identification of factors influencing thrombin generation in patients with stable angina (SA) enrolled to the coronary artery bypass grafting (CABG) surgery. Analysis of traditional (age, gender, hypertension and diabetes) and novel (fibrinogen and C-reactive protein [CRP]) risk factors and the antiplatelet therapy (aspirin 75-150 mg/d) in relation to coagulation. Patients and methods. In 135 SA patients with left main coronary artery stenosis $(>50 \%)$ or major epicardial artery stenosis $(>70 \%)$, plasma TAT levels, maximal thrombin concentration $\left(\mathrm{C}_{\max }\right)$ and endogenous thrombin potential (ETP) were determined. A marker of the platelet activation ( $\beta$-thromboglobulin) was also measured. Results. No correlations among TAT, $C_{\max ^{\prime}}$ ETP, risk factors and $\beta$-thromboglobulin were observed. Linear regression model showed that independent predictors of TAT levels were age ( $\beta=0.5 ; p=<0.0001)$, male gender and diabetes $(\beta=0.36 ; p=0.02)$. CRP independently predicted TAT and ETP $\left(\beta=-0.24\right.$ and $\beta=0.22 ; p<0.05$, respectively), while fibrinogen predicted $C_{\max }(\beta=0.21 ; p<0.05)$. Independent predictors of $\beta$-thromboglobulin were a male gender and aspirin use cessation $(\beta=0.46$; $p=0.01)$. Aspirin treatment had no effect on thrombin generation. Conclusions. Age, higher fibrinogen, CRP, diabetes and male gender influence thrombin generation and/or coagulation activation in SA patients. Plasma levels of thrombin-antithrombin complexes do not correlate with the parameters obtained using the calibrated automated thrombogram method ( $\mathrm{C}_{\text {max }^{\prime}}$ ETP).
\end{abstract}

Key words: calibrated automated thrombogram, coronary artery disease, thrombin generation, thrombin-antithrombin complex

\section{INTRODUCTION}

An important role of the coagulation system in artherosclerosis has been known since about 20 years ago [1]. The studies of ARIC give us a mass of convincing evidence that the increased fibrinogen, coagulation factor VIII and von Willebrand factor contribute to higher risks of coronary artery disease in both genders [2]. The active tissue factor (TF), which

Correspondence to:

dr biol. Ewa Stępień, Samodzielna Pracownia Biologii Molekularnej i Badań Naukowych, Krakowski Szpital Specjalistyczny im. Jana Pawła II, ul. Prądnicka 80, 31-202 Kraków, Poland, phone: +48-12-614-31-45, fax: +48-12-423-39-00, e-mail: estepien@szpitaljp2.krakow.pl Received: June 17, 2007. Accepted in final form: August 13, 2007.

Conflict of interest: none declared.

Pol Arch Med Wewn. 2007; 117 (7): 297-305

Copyright by Medycyna Praktyczna, Kraków 2007 initiates hoemostatic processes, has been detected in atherothrombotic plaques [3] and higher levels of prothrombin fragment F 1.2 (a marker of thrombin generation) have been observed in intracoronary blood samples obtained proximally and distally to the coronary atherosclerotic plaques of patients with unstable coronary artery disease [4]. The plasma levels of F 1.2 have been significantly associated with carotid intimamedia thickness, suggesting a relationship between thrombin generation and atherosclerosis development [5].

Thrombin is essential to the acceleration of the coagulation process. In normal plasma, thrombin is produced by an intricate series of proteolytic events that triggers the conversion of inactive prothrombin to an active form by prothrombinase (a complex of activated factor $\mathrm{V}$ and activated factor $\mathrm{X}$ [FXa]) in the presence of calcium ions. Thus, the thrombin plasma 
activity is not only related to the initiating level of prothrombin, but also to the kinetics of prothrombin conversion reaction and thrombin inactivation regulated by endo- and egzogenic inhibitors. In normal conditions thrombin generation is attenuated by a variety of inhibitors, which inactivate either serine proteases or cofactors. Antithrombin appears to be the most important stoichiometric inhibitor which forms equimolar complexes with thrombin molecules - TAT (thrombin-antithrombin) complexes. The level of TAT complexes measured directly in peripheral venous blood and in blood collected at the site of microvascular injury [7] reflect thrombin generation. The complexes of TAT are expressed during clot formation, and there are (alike fibrinopeptide A and F1.2 fragments) markers of thrombin activation [8,9].

Antithrombin can also inactivate the prothrombinase activity by the irreversible binding to the FXa. This inhibitory reaction is enhanced in the presence of egzogenic thrombin inhibitor - heparin [10]. Heparin triggers the prothrombotic activity both by an allosteric conformational change mechanism that specifically enhances FXa inactivation and by a ternary complex bridging mechanism that decreases fivefold the thrombin activity [10].

Thrombin generation depends on its fibrinolitic activity as well. The thrombin activity is inhibited by its relation to fibrin [11], also called antithrombin 1, and by the thrombin-thrombomodulin interactions. The process of thrombomodulin to thrombin binding diminishes its specificity to fibrinogen and enhances thrombin activity towards the thrombin-activable fibrynolysis inhibitor [12]. Thus, both coagulation and fibrinolytic cascades involve thrombin activity and thrombomodulin potentially couples and regulates them.

Complex mechanisms of thrombin generation and inhibition are regulated in plasma in a different manner involving many endo- and exogenic activators and inhibitors (heparin and its low molecular weight fractions). Acetylsalicylic acid (aspirin) plays an important role in anticoagulant activity mainly inhibiting the cyclooxygenase-dependent platelet activation. It was shown that aspirin attenuates thrombin generation, probably decreasing prothrombinase activity or by the TF inhibition [13].

Thrombin generation in vivo is modulated by different quantitative and qualitative factors: inherited antithrombin, protein $\mathrm{S}$ or $\mathrm{C}$ deficiency, single nucleotide polymorphism (prothrombin G20210A, Factor V Leiden). Environmental factors, i.e. obesity [14], age [15], oral contraception [16], and diseases: diabetes mellitus [17], hypertension [18] and coronary artery diseases [19] interact with the thrombin formation process.

A variety of laboratory methods for quantifying thrombin activity in vitro have been developed and applied successfully. Assays based on the measurement of prothrombin activation products levels (peptide F1.2) [8] and TAT levels employ the ELISA methods [9]. Despite real advantages of thrombin monitoring (i.e. specificity and sensitivity), these methods are not useful in the routine laboratory practice, they are not standardized and used only in experimental procedures.
The new commercially available method developed in the 1990s [20] and introduced by Hemker to assess the thrombogenic potential in vitro for the routine analysis is the Calibrated Automated Thrombogram (CAT) [21]. This method employs the flourogenic thrombin substrate added to platelet poor plasma (PPP), that enables the kinetic analysis of thrombin generation induced by the TF in a plasma sample. The course of the calibration factor is assessed during the complete experiment and the thrombin concentration versus time curve permits calculating various kinetic parameters: lag time $\left(\mathrm{T}_{\text {lag }}\right)$, peak height (maximal thrombin concentration $\left[\mathrm{C}_{\max }\right]$ ), an area under a curve (endogenous thrombin potential [ETP]) (Fig. 1). The calibrated automated thrombogram method is a semi automated and useful method for assessing the activity of a thrombin enzyme setting to the calibrator added.

The present study was undertaken to compare different thrombin generation assays: thrombin-antithrombin complex generation (TAT) and the calibrated automated thrombogram method (CAT) in patients with stabile angina enrolled for the coronary artery by-pass grafting (CABG) surgery. Moreover, the factors that may influence thrombin generation were investigated: the classical (age, gender, hypertension and diabetes) and the new (fibrinogen and C-reactive protein [CRP]) risk factors and the antiplatelet therapy (low dose aspirin).

\section{PATIENTS AND METHODS}

We enrolled in the study 135 consecutive patients with stable angina admitted to the Department of Cardiovascular Surgery and Transplantation of the Institute of Cardiology at the Jagiellonian University School of Medicine for elective coronary artery bypass graft surgery between January and May 2006. The mean score according to the EUROSCORE system for these elective patients was 2 points. Significant stenoses of the left main coronary artery $(>50 \%)$ or major epicardial arteries $(>70 \%)$, which were not scheduled for percutanous

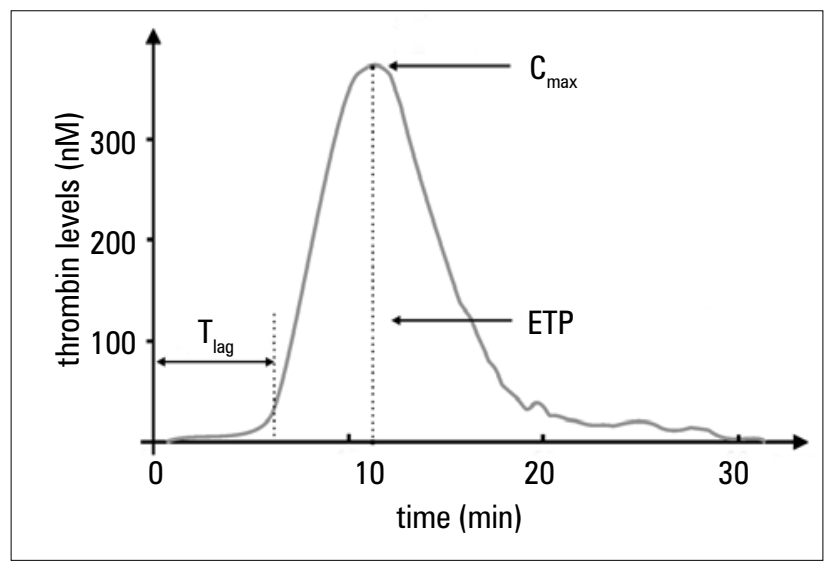

Fig. 1. Scheme of thrombin levels versus time curve. Three parameters are presented: lag time $\left(\mathrm{T}_{\text {lag }}\right)$, peak height $\left(\mathrm{C}_{\max }\right)$ and endogenous thrombin potential (ETP) 


\begin{tabular}{|c|c|c|c|}
\hline Variable & $\begin{array}{l}\text { Study group } \\
n=135\end{array}$ & $\begin{array}{l}\text { Aspirin abstained } \\
n=115\end{array}$ & $\begin{array}{l}\text { Aspirin treated } \\
n=20\end{array}$ \\
\hline Age, years (min-max) & $66(42-80)$ & $66(42-80)$ & $69(52-79)$ \\
\hline Male sex, n (\%) & $104(77)$ & $90(78)$ & $14(70)$ \\
\hline Diabetes, n (\%) & $43(32)$ & $37(32)$ & $6(32)$ \\
\hline Insulin treated & $22(16)$ & $20(17)$ & $2(10)$ \\
\hline Current smokers, n (\%) & $59(44)$ & $50(44)$ & $9(44)$ \\
\hline Arterial hypertension, n (\%) & $116(86)$ & $99(86)$ & $17(86)$ \\
\hline przebyty zawał, n (\%) & $108(80)$ & $92(80)$ & $16(84)$ \\
\hline Aspirin, $\mathrm{n}(\%)$ & $20(15)$ & - & - \\
\hline$\beta$-blockers, n (\%) & $125(93)$ & $107(93)$ & $18(90)$ \\
\hline Statins, n (\%) & $124(92)$ & $107(93)$ & $17(85)$ \\
\hline BMI $\left(\mathrm{kg} / \mathrm{m}^{2}\right)$ & $27.7(5.33)$ & $27.6(4.99)^{*}$ & $30.5(5.47)^{*}$ \\
\hline Fibrinogen (g/l) & $4.02(1.62)$ & $4.06(1.62)$ & $3.70(1.52)$ \\
\hline $\mathrm{CRP}(\mathrm{mg} / \mathrm{l})$ & $2.34(2.66)$ & $2.42(2.61)$ & $2.19(2.51)$ \\
\hline $\mathrm{TC}(\mathrm{mmol} / \mathrm{l})$ & $4.88(1.32)$ & $4.88(1.24)$ & $4.85(1.47)$ \\
\hline LDL-C (mmol/l) & $3.00(1.21)$ & $3.00(1.22)$ & $3.07(1.11)$ \\
\hline HDL-C (mmol/l) & $1.30(0.28)$ & $1.30(0.26)$ & $1.26(0.47)$ \\
\hline TG (mmol/l) & $1.51(0.55)$ & $1.47(0.62)$ & $1.55(0.33)$ \\
\hline \multicolumn{4}{|l|}{${ }^{*} p=0.028$} \\
\hline \multicolumn{4}{|c|}{$\begin{array}{l}\mathrm{BMI} \text { - body mass index, CRP - C-reactive protein, HDL-C - high density lipoprotein cholesterol, LDL-C - low density lipoprotein cholesterol, } \\
\mathrm{MI} \text { - myocardial infarction, TG - triglycerides }\end{array}$} \\
\hline
\end{tabular}

coronary intervention, were determined by the cardiac angiography. Cardiac troponin levels at enrolment were $<0.1 \mathrm{ng} / \mathrm{ml}$. Exclusion criteria included other surgical procedures on the same day, sings or symptoms of acute infections, treatment with acenocumarol, heparin or thenopyridins, a history of venous thromboembolism, a previous acute coronary syndrome within less then 3 months prior to surgery, serious concomitant diseases affecting hemostasis, like cancer, autoimmune disorders, renal insufficiency, liver disorders. Patients with CRP $>10 \mathrm{mg} / \mathrm{l}$ were excluded from the final analysis, because there was a high probability of chronic inflammatory state that may influence the relationships under investigation. Smokers were defined as individuals who self-reported cigarette smoking more than 10 daily. Diabetes were defined as fasting serum glucose $>7 \mathrm{mg} / \mathrm{l}$, the use of hypoglycemic agents, or a diabetic history regardless of the duration of the disease. Arterial hypertension was diagnosed if diastolic blood pressure exceeded $90 \mathrm{mmHg}$ and/or systolic pressure was $>140$ at least 2 times, or in the case of using antihypertensive drugs at a positive history of this disease. Patients taking aspirin were treated with acetylsalicylic acid at a dose of 7 or $150 \mathrm{mg} /$ day at least 3 days prior to the enrolment.

The ages of patients studied ranged from 42 to 80 (mean 66) years. There were $104(77 \%)$ men. Diabetes was diagnosed in $43(32 \%)$ patients, including $22(16 \%)$ on insulin therapy. Fifty-nine subjects (44\%) declared smoking, 116 had hyper- tension, $108(80 \%)$ previous myocardial infarction. The mean body mass index (BMI) was $27.7 \% \mathrm{~kg} / \mathrm{m}^{2}(5.33)$ median \pm interquartile range. Clinical data and results of laboratory tests were presented in Table 1. All patients gave their informed written consent. The study was approved by the Bioethics Committee at the Jagiellonian University.

\section{Laboratory methods}

Lipid profile was assayed by routine laboratory techniques, fibrinogen was determined using the Clauss method, highsensitivity CRP was measured by the immuno-turbidimetric method (Dimention Expand, Dade Behring, Marburg, Germany). Commercially available immunoenzymatic assays were used to determine plasma $\beta$-tromboglobulin levels ( $\beta$ TG) (Diagnostica Stago, Asnieres, France). Blood samples (3.2\% [w/v] citrate) were taken and PPP was prepared by centrifugation at $4^{\circ} \mathrm{C}$ (3000 g for $\left.10 \mathrm{~min}\right)$. Plasma aliquots were frozen and stored at $-70^{\circ} \mathrm{C}$ until use and thawed at $37^{\circ} \mathrm{C}$ before analysis.

\section{Thrombin measurement}

The blood levels of TAT were measured in citrated plasma using the ELISA method (Enzygnost TAT, Dade-Behring, 
Fig. 2. Typical example of the thrombogram recorded in normal plasma by means of the calibrated automated thrombogram. A sample with low (A) and average (B) thrombin levels

A
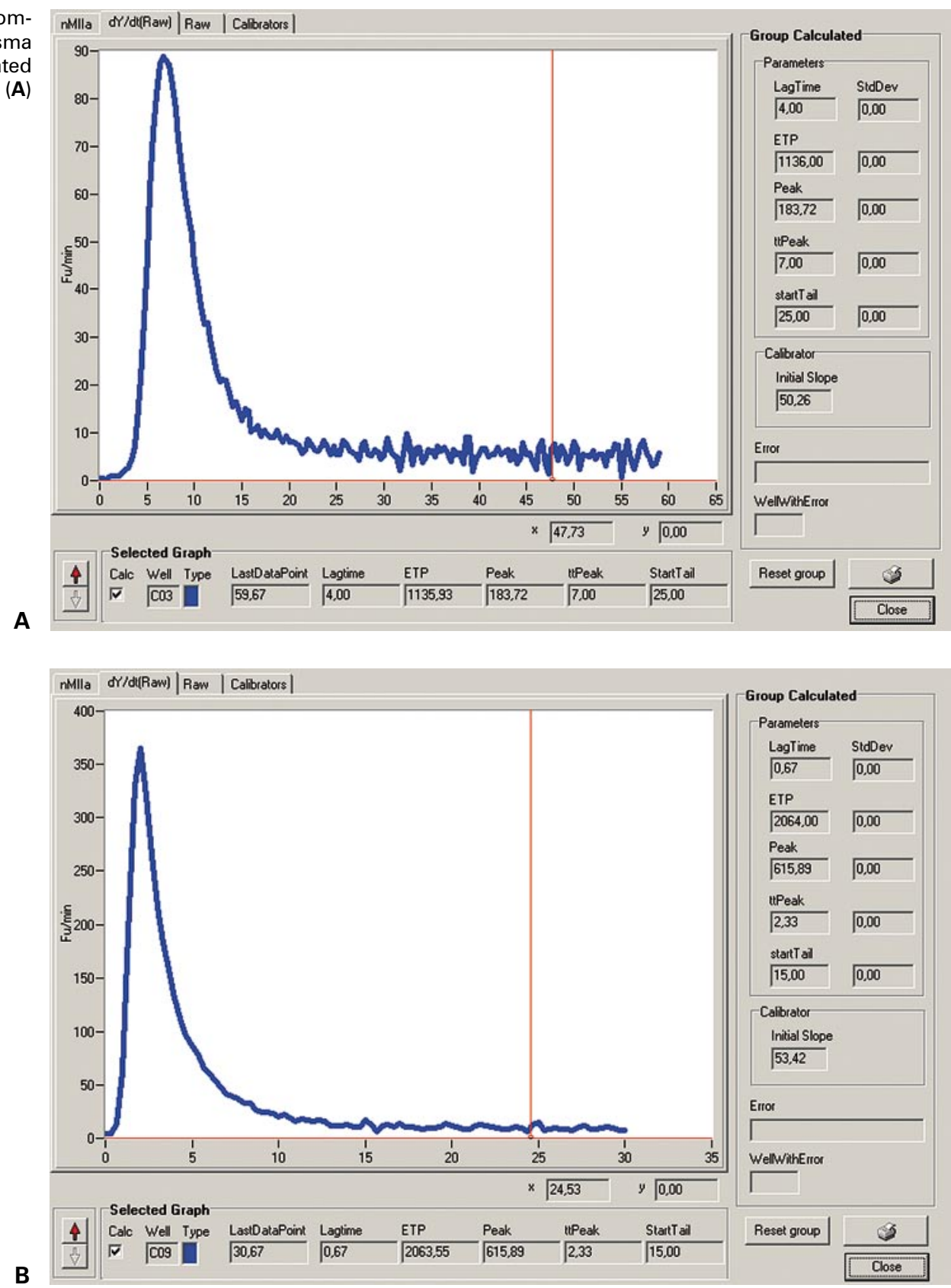

Germany). The trombogram was analysed using the CAT (Thrombinoscope BV, Maastricht, The Netherlands) according to the manufacturer's instructions in the 96-well plate fluorometer (Ascent Reader, hermolabsystems OY, Helsinki, Finland) equipped with the 390/460 filter set at a temperature of $37^{\circ} \mathrm{C}$. The eighty $\mathrm{ml}$ PPP was diluted with the $20 \mathrm{ml}$ PPP-reagent containing the $5 \mathrm{pM}$ recombinant tissue factor, 4 SM phosphatidylserine/phosphatidylcholine/phosphatidylethanolamine vesicles and the $20 \mathrm{ml}$ of FluCa solution (Hepes, $\mathrm{pH}$ 7.35, $100 \mathrm{nM} \mathrm{CaCl} 2,60 \mathrm{mg} / \mathrm{mL}$ bovine albumin, and $2.5 \mathrm{mM}$ Z-Gly-Gly-Arg-AMC). Each plasma sample was analysed in duplicates, intra-assay variability was $5.7 \%$. Each single mea- surement comprised the thrombin generation in PPP and calibrator containing 20 SI $\alpha_{2}$-macroglobulin-thrombin complex analysis. An example of a thrombogram for a low and normal thrombin activity in plasma are presented in Figure 2A and $2 \mathrm{~B}$, respectively. Data are presented as peak height $\left(\mathrm{C}_{\max }\right)$, lag time $\left(\mathrm{T}_{\text {lag }}\right)$ and endogenous thrombin potential (ETP) derived from the thrombin generation curve.

\section{Statistical analysis}

Data are expressed as medians and inter-quartile intervals or otherwise stated. The Kolmogorov-Smirnov test was used 
to determine normal distribution. The Mann-Whitney $\mathrm{U}$ test was used to test differences between groups as appropriate. The Spearman correlation model was adjusted to test the association between 2 variables with a non-normal distribution. The general multiple regression model was used to determine the predictors of TAT, ETP and $\mathrm{C}_{\text {max }}$ variables. Analysis was performed by using the STATISTICA 7.1 PL package (StatSoft, Inc. 2005). The level of significance was set at $\mathrm{p}<0.05$.

\section{RESULTS}

The group was analyzed in respect to the influence of an aspirin abstention on a thrombin generation in patients with advanced coronary artery disease before the CABG (Tab. 2). Non-taking aspirin patients ( 3 days prior to surgery) did not significantly differ from those taking low doses of aspirin (75$150 \mathrm{mg} /$ day) until surgery in respect to TAT levels (3.12 \pm 1.05 vs. $2.93 \pm 1.23 \mathrm{mg} / \mathrm{l}$, statistically non-significant [NS]), $\mathrm{C}_{\text {max }}$ ( $336 \pm 113$ vs. $313 \pm 108 \mathrm{mmol} / \mathrm{l}$, NS), lag time and ETP $(1.34$ \pm 1 vs. $1.67 \pm 0,67 \mathrm{~min} ; 1696 \pm 544$ vs. $1712 \pm 722 \mathrm{mM} * \min$, NS) and the level of $\beta$ TG $(58.5 \pm 12 \mathrm{IU} / \mathrm{ml}$ vs. $56,5 \pm 14$ $\mathrm{IU} / \mathrm{ml}, \mathrm{NS})$. The groups did not differ with respect to clinical parameters (Tab. 1), except for the BMI, which was lower in aspirin abstained patients 27.6 (4.99) vs. $30.5 \mathrm{~kg} / \mathrm{m}^{2}$ (5.47), $\mathrm{p}=0.028$.

\section{Relation between the calibrated automated thrombogram (CAT) and the thrombin- -antithrombin complex (TAT) level}

Determined in venous blood TAT complex level showed no significant correlations with lag time, $\mathrm{C}_{\max }$ and ETP in aspirin taking and aspirin refraining groups. The linear regression model (Spearman's correlation) showed only a weak but not significant association between TAT and ETP $(r=-0.36$; NS) in aspirin taking patients. Lag time and $\mathrm{C}_{\max }$ showed a significant correlation $(r=-0.22 ; \mathrm{p}=0.034)$ in the aspirin refraining group only (Tab. 3). In both groups a strong correlation was observed between $\mathrm{C}_{\text {max }}$ and ETP $(\mathrm{r}=0.74$; $\mathrm{p}<0.001$ vs. $\mathrm{r}=0.75, \mathrm{p}<0.001)$

\section{Relation between platelet activation and thrombin activation}

A marker of $\beta$ TG was not correlated with the TAT and atherosclerosis risk factors, like fibrinogen and CRP (not shown). There were no associations between the CAT parameters $\left(C_{m}\right.$ and ETP). In contrast, the correlation between $\beta$ TG and $T_{\text {lag }}$ was observed $(\mathrm{r}=-0.20 ; \mathrm{p}=0.02)$ and in aspirin refraining patients a correlation coefficient was higher $(\mathrm{r}=-0.30 ; \mathrm{p}=$ 0.005 ) than in the aspirin taking group (Tab. 3). The general multiple regression analysis showed that male gender and aspirin abstention for a total of 135 patients were independently associated with $\beta$ TG: $\beta=0.46(\mathrm{p}=0.01)$.

\section{Relation between risk factors and thrombin generation}

The model of general multiple regression showed that age and male gender together with appearing diabetes were the strongest predictors of TAT complexes in venous blood, respectively: $\beta=0.5(\mathrm{p}=0) ; \beta=0.36(\mathrm{p}=0.02)$. Insulin treated diabetes predicted TAT levels similarly $(\beta=0.38 ; \mathrm{p}=$ 0.03). High CRP levels and an aspirin treatment were weaker, but significant predictors: $\beta=0.17(\mathrm{p}=0.04)$ and $\beta=-0.24$ $(\mathrm{p}=0.03)$, respectively.

In the Calibrated Automated Thrombogram method, fibrinogen and male gender together with appearing diabetes were significant predictors of $\mathrm{Cmax}$, a standardized $\mathrm{b}$ parameter was: $\beta=0.21(p=0.039)$ and $\beta=0.4(p=0.023)$ respectively. The insulin treatment diminished this relation in diabetes patients ( $\beta=0.02$; NS). In contrast, high CRP levels $(\beta=0.22 ; p=0.029)$ and male gender with appearing diabetes $(\beta=0.38 ; \mathrm{p}=0.035)$ predicted ETP in the study group. In insulin treated patients a standardized $b$ parameter was reduced. There was no association between arterial hypertension and thrombin activation in the analyzed group.

Table 2. Comparison of mean thrombin generation parameters in patients with advanced coronary artery disease treated with aspirin and aspirin abstained

\begin{tabular}{llll} 
Variable & $\begin{array}{l}\text { Study group } \\
\mathbf{n}=\mathbf{1 3 5}\end{array}$ & $\begin{array}{l}\text { Aspirin abstained } \\
\mathbf{n = 1 1 5}\end{array}$ & $\begin{array}{l}\text { Aspirin treated } \\
\mathbf{n}=\mathbf{2 0}\end{array}$ \\
\hline TAT in venous blood $(\mu \mathrm{g} / \mathrm{l})$ & $3.07(1.06)$ & $3.12(1.05)$ & $2.93(1.23)$ \\
\hline $\mathrm{C}_{\max }(\mu \mathrm{mol} / \mathrm{l})$ & $337(116)$ & $336(113)$ & $313(108)$ \\
\hline $\mathrm{T}_{\text {lag }}(\mathrm{min})$ & $1.34(1)$ & $1.34(1)$ & $1.67(0.67)$ \\
\hline ETP $\left(\mathrm{mM}^{*} \mathrm{~min}\right)$ & $1704(583)$ & $1696(544)$ & $1712(722)$ \\
\hline$\beta T G(\mathrm{IU} / \mathrm{ml})$ & $48(12)$ & $58.5(12)$ & $56.5(14)$ \\
\hline
\end{tabular}

$\beta T G$ - $\beta$-thromboglobulin, $C_{\text {max }}$ - maximal thrombin concentration, ETP - endogenous thrombin potential (an area under the thrombin concentration versus the time curve), TAT - thrombin-antithrombin complex, $\mathrm{T}_{\text {lag }}$ - lag time peak height 
Table 3. Correlations between parameters and platelet activation in patients with advanced coronary artery disease treated with aspirin and aspirin abstained. The Spearman correlation model was adjusted

\begin{tabular}{|c|c|c|c|c|c|c|}
\hline & \multicolumn{3}{|c|}{ Aspirin abstained } & \multicolumn{3}{|c|}{ Aspirin treated } \\
\hline & $\mathrm{C}_{\max }(\mu \mathrm{mol} / \mathrm{l})$ & $T_{\text {lag }}(\min )$ & $\mathrm{ETP}\left(\mathrm{mM}^{*} \mathrm{~min}\right)$ & $C_{\max }(\mu \mathrm{mol} / \mathrm{l})$ & $T_{\text {lag }}(\min )$ & ETP $(m M * m i n)$ \\
\hline TAT $(\mu \mathrm{g} / \mathrm{l})$ & 0 & 0.07 & -0.07 & -0.18 & 0.11 & -0.36 \\
\hline$C_{\max }(\mu \mathrm{mol} / \mathrm{l})$ & - & $-0.22^{*}$ & $0.74^{*}$ & - & -0.38 & $0.75^{*}$ \\
\hline $\mathrm{T}_{\text {lag }}(\min )$ & $-0.22^{*}$ & - & 0.12 & -0.38 & - & -0.18 \\
\hline $\mathrm{ETP}\left(\mathrm{mM}^{*} \min \right)$ & $0.74^{*}$ & 0.12 & - & $0.75^{*}$ & -0.18 & - \\
\hline$\beta T G(I U / m l)$ & 0.07 & $-0.30^{*}$ & -0.07 & 0.06 & 0.09 & -0.25 \\
\hline
\end{tabular}

${ }^{*} \mathrm{p}<0.05$

Abbreviations - see Table 2

\section{DISCUSSION}

In the present study thrombin level and kinetics were assessed in vitro in PPP obtained from patients with advanced coronary artery disease. Two methods for the thrombin generation measurement were applied: the method of determining TAT complexes and the calibrated cutomated chrombogram method.

The level of TAT expresses the kinetics of antithrombin binding to an active thrombin enzyme. The final TAT level depends on the thrombin activity, its ability to antithrombin binding and accessibility of antithrombin in plasma. Elevated TAT complexes levels were observed in patients with critical limb ischaemia [22], chronic heart disease [23], septic shock syndrome [24] and acute ischemic stroke [25]. It was observed that high TAT levels may predict mortality in the chronic heart disease group after the adjustment to classic risk factors [23]. In our study, TAT levels in venous blood obtained from advanced coronary artery disease patients were $3.07 \pm 1.6 \mathrm{mg} / \mathrm{l}$ and did not differ between groups treated with aspirin and aspirin abstained 3 days prior to the CABG. Intriguingly, we have noticed that TAT levels in our study were similar to that observed by Ono and coworkers [25] in their control group $(2.94 \pm 0.42 \mathrm{mg} / \mathrm{l})$. We suggest that balanced levels of TAT may be caused by the routine statin treatment, as $92 \%$ of our patients took simvastain regularly in a dose of at least $20 \mathrm{mg} / \mathrm{d}$. Undas and coworkers [26] observed in the model of microvascular injury that this dose of simvastatin attenuates the formation of F1.2 fragments in patients with advanced coronary artery disease. The three-day simvastatin administration significantly retarded prothrombin activation at the site of injury and plasma TAT, and a tendency toward lower posttreatment TAT values was observed [27].

The study group varied in respect to age, sex, diabetes, arterial hypertension, CRP and fibrinogen levels (Tab. 1.), thus we decided to analyze the influence of these risk factors on thrombin level and kinetics of generation processes measured by means of the CAT. We have noticed that age and the male sex are the strongest predictors of TAT levels. The role of aging in elevated thrombin generation was previously observed in controls [15] and in patients with ischemic stroke [25]. There are no data concerning the role of gender in the process of thrombin formation in patients scheduled for the CABG. We supposed that other factors directly related to sex: a lifestyle, smoking and diabetes, might contribute to its prothrombotic activity. In contrast, the relation between age and the CAT parameters was weaker. Fibrinogen and the male sex were the only predictors of $\mathrm{C}_{\max }$. We found only one report concerning thrombin generation and fibrinogen level [28]. In this report the reduced $\mathrm{C}_{\max }$ and ETP were observed after the daily omega- 3 polyunsaturated fatty acids intake. This effect was determined by the $312 \mathrm{Ala}$ polymorphism in the fibrinogen- $\alpha$ gene.

We found that CPR is a predictor of high TAT levels and increased ETP. Association between high CRP levels and fibrin formation, thrombin generation and fibrinolysis were previously reported [29,30]. It might be suggested that CRP plays a role in the coagulation cascade: by effecting thrombin activity and/or by the modulation of the thrombin inhibitors availability. Thus CRP may influence the fibrin structure, its permeability and susceptibility to lysis [31].

The levels of TAT did not correlate with $\mathrm{C}_{\max }$ and ETP, probably because both diagnostics methods differ from each other in action. We observed anobvious correlation between $\mathrm{C}_{\max }$, ETP and $\mathrm{T}_{\text {lag }}$ only (Tab. 3). In the CAT an increased production of exogenous thrombin substrate is detected. This method is based on the kinetic analysis of a signal obtained by the TF factor induced endogenous thrombin and exogenous calibrator activation. Each single measurement comprises the thrombin generation and calibrator analysis and it estimates a real thrombin activity regulated by the competition between exo- and endogenous thrombin substrates (including thrombin itself). Thus, an increased substrate level prolongs lag time and elevates an area under the thrombin level versus the time curve [32]. Taking these facts into consideration, we are not surprised that the TAT and the CAT parameters do not correlate and we may conclude that we cannot use both methods alternatively. The introduction of the CAT to the routine di- 
agnostics requires validation of this method with reference to concomitant diseases.

A limited number of patients (20 aspirin taking and 115 aspirin abstained prior to $\mathrm{CABG}$ ) did not allow us to analyze the difference in thrombin generation between subgroups. We considered the correlation coefficients within each group only. In our study, significant correlations between $\mathrm{T}_{\mathrm{lag}}$ and $\mathrm{C}_{\max }$ in the aspirin refrained group and between ETP and $\mathrm{C}_{\max }$ in both groups were found. It may be concluded that the process of thrombin generation in vitro proceeded similarly in both groups, but it was not possible to assume whether the aspirin prohibition prior to the surgery influenced that process. In normal conditions, at least $50 \%$ of platelets (or more) are inhibited on the third day after an aspirin intake, thus even 3 days of an aspirin abstention do not significantly alter the previous attenuated platelet activity. Comparable TAT levels in both groups were caused by "aspirinization" of platelets, probably. On the other hand, the TAT may be repressed in the COX-1 independent way by a specific acetylation of plasma proteins, especially the AT [33].

In patients with abstained aspirin the marker of $\beta \mathrm{TG}$ was significantly associated with $\mathrm{T}_{\text {lag }}(\mathrm{r}=-0.33 ; \mathrm{p}=0.005)$. In aspirin treated patients this association was weaker and it was possibly related to the inhibition of COX-1. In aspirin abstainers, the COX-1 activity is not regulated by aspirin, thus the platelets activation affects lag time in this group.

We found that diabetes is an independent predictor of thrombin generation expressed as the TAT complexes level and the rise of thrombin generation in time (ETP). Diabetes facilitates inflammatory processes accompanying atherosclerosis: an increased formation of superoxide anions [34] and a decreased nitric oxide synthase activity [35] are observed. An enhanced platelet activity results in elevated thrombin generation in diabetics [17], which may cause a high risk of thromboembolization in patients undergoing the CABG. It is known that a high thrombin activity attends insulin resistance [14]. In the present study we observed that insulin treatment is related with the TAT levels, but there is no association with the CAT parameters. In our statistic model the share of insulin treatment (a qualitative variable) is probably influenced by other continuous predictors (fibrinogen, CRP). The authors suggest that the statistic power of these predictors diminishes the relation between insulin treatment and $\mathrm{C}_{\max }$ and ETP comparing to diabetes effect.

Summarizing, we showed in our study that risk factors like age, high fibrinogen and CRP levels (acute phase proteins), diabetes and male gender are connected with elevated thrombin generation and/or activity in patients with advanced coronary artery disease scheduled for the coronary artery by-pass grafting surgery. We also demonstrated that two assays for the coagulation markers: CAT and TAT can not be used interchangeable in this group.

\section{ACKNOWLEDGMENTS}

The authors are grateful to Dr Tim van Asten from Thrombinoscope BV (The Netherlands) for the support with the CAT reagents and equipment, and valuable advice on data analysis. These experiments were financed by the state Committee for Scientific Research (KBN), Warsaw, Poland, grant No. N403 $03731 / 2198$.

\section{REFERENCES}

1. Meade TW, Mellows S, Miller GJ, et al. Haemostatic function and ischaemic heart disease: principal results of the Northwick Park Hart Study. Lancet. 1986; 2: 533-538.

2. Folsom AR, Wu KK, Rosamond WD, et al. Prospective study of hemostatic factors and incidence of coronary heart disease: the Atherosclerosis Risk in Communities (ARIC) study. Circulation. 1997; 96: 1102-1108.

3. Marmur JD, Thiruvikraman SV, Fyfe BS, et al. Identification of active tissue factor in human coronary atheroma. Circulation. 1996; 94: 1226-1232.

4. Ardissino D, Merlini PA, Bauer KA, et al. Thrombogenic potential of human coronary atherosclerotic plaques. Blood. 2001; 98: 2726-2729.

5. Páramo JA, Orbe J, Beloqui 0 , et al. Prothrombin fragment $1+2$ is associated with carotid intima-media thickness in subjects free of clinical cardiovascular disease. Stroke. 2004; 35: 1085-1089.

6. Aleil B, Meyer N, Wolff V, et al. Plasma glycoprotein V levels in the general population: normal distribution, associated parameters and implications for clinical studies. Thromb Haemost. 2006; 96: 505-511.

7. Stępień E, Szułdrzyński K, Branicka A, et al. Allel PIA1/A2 beta3 integryny wiąże się ze zwiększona generacja trombiny u pacjentów z chorobą wieńcową leczonych aspiryną - wpływ leczenia statynami. Pol Arch Med Wewn. 2007; 1-2: 33-40.

8. Aronson DL, Stevan L, Ball AP, et al. Generation of the combined prothrombin activation peptide (F1-2) during the clotting of blood and plasma. J Clin Invest. 1977; 60: $1410-1418$

9. Hoek JA, Sturk A, Cats JW, et al. Laboratory and clinical evaluation of an assay of thrombin-antithrombin III complexes in plasma. Clin Chem. 1988; 34: 2058-2062.

10. Chuang YJ, Swanson R, Raja SM, et al. Heparin enhances the specificity of antithrombin for thrombin and factor $\mathrm{Xa}$ independent of the reactive center loop sequence. Evidence for an exosite determinant of factor Xa specificity in heparin-activated antithrombin. J Biol Chem. 2001; 276: 14961-14971.

11. de Bosch NB, Mosesson MW, Ruiz-Sáez A, et al. Inhibition of thrombin generation in plasma by fibrin formation (Antithrombin I). Thromb Haemost. 2002; 88: 253-258.

12. Bajzar L, Nesheim M, Morser J, et al. Both cellular and soluble forms of thrombomodulin inhibit fibrinolysis by potentiating the activation of thrombin-activable fibrinolysis inhibitor. J Biol Chem. 1998; 273: 2792-2798.

13. Undas A, Brummel-Ziedins KE, Mann KG. Antithrombotic properties of aspirin and resistance to aspirin: beyond strictly antiplatelet actions. Blood. 2007; 109: 22852292.

14. Romano M, Guagnano MT, Pacini G, et al. Association of inflammation markers with impaired insulin sensitivity and coagulative activation in obese healthy women. $\mathrm{J}$ Clin Endocrinol MeTab. 2003; 88: 5321-5326.

15. Bauer KA, Weiss LM, Sparrow D, et al. Aging-associated changes in indices of thrombin generation and protein $C$ activation in humans. J Clin Invest. 1987; 80: 1527-1534.

16. Rosendaal FR, van Hylckama Vlieg HA, et al. Estrogens, progestogens and thrombosis. J Thromb Haemost. 2003; 1: 1371-1380.

17. Aoki I, Shimoyama K, Aoki N, et al. Platelet-dependent thrombin generation in patients with diabetes mellitus: effects of glycemic control on coagulability in diabetes. J Am Coll Cardiol. 1996; 27: 560-566.

18. Corseaux $D$, Ollivier $V$, Fontaine $V$, et al. Hemostasis imbalance in experimental hypertension. Mol Med. 2002; 8: 169-178.

19. Musiat, J, Pająk A, Undas A, et al. Thrombin generation markers and coronary heart disease risk factors in a Polish population sample. Thromb Haemost. 1997; 77: 697700.

20. Hemker HC, Wielders $\mathrm{S}$, Kessels $\mathrm{H}$, et al. Continuous registration of thrombingeneration in plasma, its use for the determination of the thrombin potential. Thromb Haemost. 1993; 70: 617-624

21. Hemker HC, Giesen $P$, AIDieri R, et al. The calibrated automated thrombogram (CAT): a universal routine test for hyper- and hypocoagulability. Pathophysiol Haemost Thromb. 2002; 32: 249-253.

22. Cassar K, Bachoo P, Ford I, et al. Markers of coagulation activation, endothelial stimulation and inflammation in patients with peripheral arterial disease. Eur J Vasc Endovasc Surg. 2005; 29: 171-176.

23. Marcucci R, Gori AM, Giannotti F, et al. Markers of hypercoagulability and inflammation predict mortality in patients with heart failure. $J$ Thromb Haemost. 2006; 4: 1017-1022. 


\section{ORIGINAL ARTICLES}

24. Psuja P, Zozulinska M, Turowiecka Z, et al. Plasma markers of hypercoagulability in patients with serious infections and risk of septic shock. Clin Appl Thromb Hemost. 2002; 8: 225-230.

25. Ono N, Koyama T, Suehiro A, et al. Clinical significance of new coagulation and fibrinolytic markers in ischemic stroke patients. Stroke. 1991; 22: 1369-1373.

26. Undas A, Brummel K, Musial J. Simvastatin depresses blood clotting by inhibiting activation of prothrombin, factor $\mathrm{V}$, and factor XIII and by enhancing factor Va inactivation. Circulation. 2001; 103: 2248-2253.

27. Undas A, Celinska-Löwenhoff M, Brummel-Ziedins KE, et al. Simvastatin given for 3 days can inhibit thrombin generation and activation of factor $V$, and enhance factor Va inactivation in hypercholesterolemic patients. Arterioscler Thromb Vasc Biol. 2005; 25: 1524-1525

28. Vanschoonbeek K, Feijge MAH, Paquay M, et al. Variable hypocoagulant effect of fish oilintake in humans: modulation of fibrinogen level and thrombin generation. Arterioscler Thromb Vasc Biol. 2004; 24: 1734-1740.

29. Reganon E, Vila V, Martinez-Sales V, et al. Inflammation, fibrinogen and thrombin generation in patients with previous myocardial infarction. Haematologica. 2002 87: 740-745.

30. Niccoli G, Biasucci LM, Biscione $C$, et al. Instability mechanisms in unstable angina according to baseline serum levels of C-reactive protein: The role of thrombosis fibrinolysis and atherosclerotic burden. Int J Cardiol. 2007 Jan 29; [Epub ahead of print].

31. Undas A, Plicner D, Stępień $E$, et al. Altered fibrin clot structure in patients with advanced coronary artery disease: a role of C-reactive protein, lipoprotein(a) and homocysteine. J Thromb Haemost. 2007; 5: 1988-1990.

32. Butenas S, Mann KG. Caution in the interpretation of continuous thrombin generation assays. J Thromb Haemost. 2007; 5: 1084-1085.

33. Villanueva GB, Allen N. Acetylation of antithrombin III by aspirin. Semin Thromb Hemost. 1986; 12: 213-215.

34. Schaeffer G, Wascher TC, Kostner GM, et al. Alterations in platelet $\mathrm{Ca} 2+$ signalling in diabetic patients is due to increased formation of superoxide anions and reduced nitric oxide production. Diabetologia. 1999; 42: 167-176.

35. Rabini RA, Staffolani $R$, Fumelli $P$, et al. Decreased nitric oxide synthase activity in platelets from IDDM and NIDDM patients. Diabetologia. 1998; 41: 101-104. 